\title{
Traditions of folk culture and education
}

\author{
Marina Galkina ${ }^{1, *}$ \\ ${ }^{1}$ Moscow Region State University, 10A, Radio str., 105005, Moscow, Russia
}

\begin{abstract}
The research on problems on preserving identity of tradition folk art and craft for strategic objective to design modern methods and tools in order to contribute to the creation of an education process. Experience was acquired in conducting relevant large-scale festivals, competitions, science conferences clearly demonstrated the younger generations growing ability in ownership to provide effective Russian Art cultural. Increased attention to realize workshops with Folk art and craft in the Moscow region system of additional education indicated positive dynamic for introducing teachers and children's through period 2010-2020 years. It is notable for protection cultural historical heritage areas of Moscow region, which directed towards traditional Russian decorative Art especially over the past years.
\end{abstract}

\section{Introduction}

The idea of revival, preservation and development of our national culture, based on human values, has become part of culture policy and educational system.

Our goal is to show the place and uniqueness of Folk Art is thriving.

There has been a growing understanding in the recent decades that folk traditions are a real basis of the Russian culture and education.

As our history shows, their adoptive and educational potential is universal, which leads to their multifunctional usage, They are able to show the child into the traditional culture of our motherland by revealing the most distinguished features of the national esthetics and culture. However, the bigger part of our national heritage, mostly local crafts, is still unknown even to local historians and ethnographers.

\section{Material and Methods}

Education based on traditions contributes to the nation's preservation and development, which makes a teacher's role enormous: teachers are conductors of not knowledge only, but of national values and traditions.

Supervision coordination of the Moscow region art centers is provided by the Regional esthetics Centre for children at the Moscow State Region University. Its activity is based on tight connection between scientific and practical methods, as well as providing teachers and craftsmen from the region with the high-quality patterns and models of the educational process.

\footnotetext{
* Corresponding author: galkina.marina@gmail.com
} 
The leading aim of the Regional Program is improving teachers skills, involving them into fruitful exchange of experience and knowledge in the framework of the program "Child in the world of traditional culture», encourage their usage of local folklore traditions in educational process. There is a whole system of organizing and practical work which includes one-day conferences? Seminars and vaster-classes within the dynamic and efficient exhibition contest (original called «moviky» by the contestants). These conferences proved to be the most effective and are now part of the long-term project of the Moscow teachers whose purpose is to introduce local traditions and crafts into everyday educational process.

The system of extra-curricular education optimizes cultural activities providing more freedom and independence in the given framework. The educational process is organized on conditions enabling students to form value-based ties with the national culture. It means providing beneficial conditions for further development of traditions, passing them from generation to generation, forming cultural values, interests and demands, shaping ideas, tastes and preferences.

\section{Exhibitions and Education}

Traditional culture is form in which every nation keep and develops their experience, values, outlook and is therefore an irreplaceable means of education. The culture of ceremonies and celebrations includes not only festivals, holydays and events, but general work and leisure ethics, a complicated system of values and customs, as well as traditional methods of upbringing by means of establishing well-balanced and national and local traditions to teaching children to love their «little motherland», respect their ancestors and their work, without which it is impossible to receive a patriotic, highly moral and creative personality.

Conferences, seminars, exhibitions-competitions, and workshops, all of the dynamic and effective contest-exhibition, proved to be the most beneficial for our teachers aimed at developing real traditions of ethnic and harmony.

They are part of the long-term project aiming at introducing original traditions of folk art into everyday practice of extra-curricular education.

The main purpose of the conferences is improving qualifications of teachers, teacher trainers and managers, acquainting them with new methods and principles of teaching local crafts, exchange of experience and ideas. The seminars demonstrate possibilities of local crafts, provide the unique opportunities to participants with information about new issues, collections of craftwork in the museums of Moscow and Moscow region, Sergiev Posad, Sankt Petersburg, establish contacts between local specialists (historians, museum scientists, collectors, craftsmen), select students most interesting works for all-Russia or international festivals.

Each of conferences becomes a unique event for the cultural life of the Moscow region, and unites people of great professional and spiritual potential. This process draws upon scientific evidence, uncovers current beliefs and assumptions that underline our choices and encourages creative thinking about a wide range of possibilities.

\section{Results}

We have conducted an educational experiment with teachers and children's of 50 centers of creativity from 50 districts of Moscow region over the period of 2007 to 2020, with $4000+$ participants involved. Some of them are successful students in Art university's, acting in the field of folk art, design and fashion. The most eminent (brilliant) have been awarded 
certificate's of professional recognition in pedagogical education. Research by the region center of folk art and craft indicates that young teachers have a significantly higher then average success rate and a positive track record in professional field and creative assignments, based on the statistical data of the Department of Fine Arts and Folk Crafts of GOU VO MO Moscow State Regional University and Russian Academy of Art.

As the final product of the contest, each year a special book containing the winning art and craft illustrations is published. The winners were selected by a committee of experts and were presented with awards by the Region Minister of education.

The seminar «Folk calendar» was invited by the teachers of the children club in Lytkarino. Marina Sacharova, a teacher of the club, presents traditional ceremonial culture and engage all gests to the world of traditional celebrations, festivals, folk games, ceremonies and dances to children.

The children club in the town Pushkino is a center of standing traditions of pottery and clay toys. Contributing effectively to creative dialogue involves analysis, creative reflection collacting lessons learned to provide technological inputs. Alexandra Abrosimova, a most experienced teacher, started a school of traditions clay toys, which originated in the ancient times and still popular nowadays. Another children's club from the Klin presented «Moscow clay toys» studio. Successful teachers Kourilkina Tatiana and Pechnikova Larisa suggest turning a complicated technological chain into a fairy -tail, which makes pottery a real treat for children. The collection of «russian gromotushka» cats (toy rattles) from Vysokovo can be considered a local craft from the Moscow region. The main tasks of every lesson is to engage teachers and children's in creative process and self-expression irrespective of social background.

Conferenses and work shops in Pavlovsky Posad are famous by the unique school of showls and printed calicoes of Honored Artists Victor Zubritskiy, Zlata Olshevskaya, Valentina Inozemtseva. The composition of the drawing on Pavlovsky shawls depends on the execution technology in the material. It is industrial art in which is important to preserve beauty and grace. Applying high level experience of artist in the final stages of design will help yield a unique painting. Great masters always showed great attention to the coloristic effects and details in creative work. Special secrets of achiving the most popular Near Earth coloristic effects - all of those issues are of great and direct importance from participants of workshops.

The unique art of painting by wood is famous of wide application through Russia and it is difficult to find a corner in our huge country without special painting subjects.

In recent years the system of supplementary education has expended painting by wood intensively, leading to the creation of children's education. Our general goal is to support intensive care for the preservation and development of folk art traditions and increzing importants children's and students creativity.

The main idea during process of painting five local nesting dolls participants, solve the following tasks- imagination and fantasy development development and gaining a skill by brush painting on the round wood billet, training of the fine motor skills by hands.

Conducting master classes for a limited time 30-40 min. The head challenge a successful result - finished product. Skillful action of leader allows all participants to get there and achieve the objective of the painting with taking into account personal preferences.

We attached great importance to the success of workshop through preparation of materials with instruments and clear adherence to temporary parameters $-\mathrm{m}$ mandatory condition.

To formulation the problem -5 min., application background pattern -10 min., horse painting and ornamentation $-20 \mathrm{~min}$, drying and lacquer $-5 \mathrm{~min}$. 
Positive experience of workshops for painting matryoshka doll demonstrated developmental characteristics and creativity. Participants in age 10-12 years more successful in first and second step, but third and forth steps cause problems. It is necessary to support the process in the form of an additional materials - posters, foto, ornamental patterns and coloristic compositions. When master (craftsmen) helps for participants verbal - the level of engagement increasing in the process of carry out workshop. It is important to provide be able to contribute actively.

Workshop "carving by wood" for children in age 10-12 years. Traditions of carving by wood in Russia has deep national, cultural and arts roots. Free access to wood have allowed masters to shape high level creativity over the centuries. Every subject in architecture, in interior was richly decorated and multicolored by ornamental patterns. Although continuing work with original wood, master simultaneously studied different qualities and every time opened new possibility of gorgeous material. Because wood has expressive structure of the tree, it would have been identify and highlight individual effect.

Even the first researches had mentioned that the peoples of Russia are virtuosos of the wood art. Woodcarving and painting have always been organically combined with shape.

During the workshop master suggested to do assignment with ornamental composition in circle surrounded by the ring-shaped elements (illustration attached) with groove on a tablet of lime. Perfect tools are very important part. Special forms of knives and chisel ensure optimal power transfer, which provides high cutting performance. Responsible for safety regulations is ensured by master. We are sure about possibility to teach children of decorative wood-carving at the age 8-10 year by our experience. The tree's wooden sity is extremely high, which makes it possible for creativity. Bogorodskaya, Kudrinskaya, Abramtsevskaya traditional wood carving now are relevant to the development of folk art and craft education by teachers. Teachers integrated lessons of wood carving with painting by wood Gorodetskaya, Boretskaya, Permogorskaya - as a result of innovative idea.

In 2018, on the occasion of the 10th Creativity Festival Vidnoe, "Impuls" run a workshop "Processing of ceramics and painting" for children in age 10-12 year, with the Region Center. The events during the festival were attended by 450 visitors.

Experimental work to replicate the unique model of tradition pottery vase draws attention to plastic harmony previous requests to the local archaeology, which fascinating ethnographic identity and culturally differentiated variants. Researchers are choosing different approaches in ceramics - including reconstruction of traditions perfection formsmaking glazed earthenware clay products consisting in carrying out rapid and high-quality baking and at the same time creation author's toy.

Workshops by ceramics divided into two main types - creation unique quality ceramic souvenirs from red and white clay ore colors the ornament by acrylic or tempera pigments. Following on process craftsmen usually used for making various forms of little bell, pennywhistle, including faster potter's wheel and special tools for amazing examples of vases. Fine ceramic plastic - animalized toys in the image and likeness of traditional samples drew attention of participants to the need to use three-dimensional reasoning. Increasingly, this experience challenges teachers team to draw on this tradition and to see it as a phenomenon of differences but rather as one of diversity in which each separate element is playing a significant crucial importance for enriching our society.

This program is been implemented with participants of 70 regions around Moscow.

1. The method of system of conferences was organized by the team members of universities specialists on a professional basis. The aim of this project is to provide unique opportunities for teachers professional development in an universities environment.

2. On the basis of this analysis, the authors of the training material and workshop leaders, all together with professionals from the Academy, put forward recommendations 
for further work. The organization focused its work at the issue of children in Russian tradition. The report of experience had been circulated to all members, had made it possible to initiate a thorough study of these important problem.

General mission of this region program is to foster the development of knowledge, expand practices that can offer new perspectives, and ensure growth in understanding and appreciation of different specialists. Collection of programme performance information, based on reliable methodologies. Should be made systematic in order to assess envisaged results are been achieved

4. Master classis programs provide the unique opportunity to take learning outside of the classroom and study both theory and techniques through activity's in folk art expedition.

5. This region program will ensure that the excellence, vitality and diversity of the Russian folk art are effectively showcased by exhibitions, competitions and conferences.

6. This region project will allow to build stronger ties through global partnerships in the folk art and craft workshops.

7. The opportunity for the teachers to be engaged in creative work enabled education organizations and individual scientists to enter the international scientific journals.

1. Lessons learned are presented, as well as recommendations for consideration by the respective methodic teams in formulation of the regional program's. A comprehensive and in-depth post implementation reviews enable the use of work shops, lessons learned for the benefit of future deployments.

This experience will be fed into educational policy-level initiatives.

2. Experimental unique experience methods and technologies like system of educational program.

3. High level of education activity.

4. Step by step instructions specific conditions (features) of organization lessons with children.

5. The main requirement for the authors of the projects is to submit written and visual material, or video presentation.

\section{Discussion}

In the above described proprietary integrated methodology workshops of Russian Folk Art and craft for increasing interest for professional development, experience challenges teachers to draw tradition in progressive pedagogical education has been generalized. As a result, we consider the scientific works of V.A. Baradulin, R. S. Ye. Ignatiev, V.V Koreshkov, V.S Kuzin, S.P. Lomov, N.N. Rostovtsev, D.A. Khvorostov, Ye. V. Shorokhov as fundamental for the modern educational system of Russia.

The historical, theoretical, and practical aspects of organizing workshops of Russian Folk Art like innovative idea that have contributed to shaping our integrated methodology are covered by M.R. Belousov, M.O. Denisova, I.A. Bezsina, E. I. Vasil'eva, N.Yu. Dunaeva, P.E. Serov, M.K. Lomakin, and others in their works.

The integrated methodology is also based on experiments and practical, creative, and educational experience of such original and executive methodic, based on research expedition for ancient centers of Russia, including reconstruction of traditions perfection forms, Folk Art craftsmen as Antishin N. B., Arefyeva G. I., Artamonov R., Arshinov Ya.V., Bezobrazov A. O., Bespalova L. F., Varganov A. N., Varunin P. G., Vikhrova N. V., Golubeva A. N., Gorodnicheva T. D., Grushetskaya T., Drozdovsky A. A., Ermilov V., Ilina S. V., Kiselev V. N., Kovalev O. V., Korshunova I. V., Koryeva T. G., Kukulieva K. V., Litvinova O. N., Makarov E., Malyshev D., Muravyev N. S., Polezhaev A., Sokolov S. 
F., Spiridonov A., Staroverova E. N., Polosin A. E., Tereshina A. F., Trifonov V. I., Tumanova E., Ulasevich S. N., Frolova N. N., Tsagareishvili V., Yurtov V. V., etc.

\section{Acknowledgements}

Clarity of purpose of work shops is increasing the motivation to acquisition of new methods and technologies for ensuring of quality and efficiency for educational activities.

- discussion authors experimental technologies,

- It is an initiative aimed at redefining the model of educational practices

And renewing tasks:

- The regional level, several initiatives in the form of conferences information seminars have given rise to fruitful exchanges of experience.

- Teachers that are father ahead in certain kinds of technologies and practices could look to demonstrate and share capabilities and capacities.

- Approaches challenges and opportunities with a clear perception of the impact on others and aiming to create win-win situations.

A coordination and review of the activities of Moscow Regional center showed that impressive results had been achived. The possibility of an effective alternative to traditional methods of teaching in education is proved by regular screenings and participated in allRussian and international workshops.

Table 1. The number of participants of master classes at festivals and competitions.

\begin{tabular}{|c|c|c|c|c|c|c|c|c|c|}
\hline Stage $\backslash$ Year & $\mathbf{1 1 - 1 2}$ & $\mathbf{1 2 - 1 3}$ & $\mathbf{1 3 - 1 4}$ & $\mathbf{1 4 - 1 5}$ & $\mathbf{1 5 - 1 6}$ & $\mathbf{1 6 - 1 7}$ & $\mathbf{1 7 - 1 8}$ & $\mathbf{1 8 - 1 9}$ & $\mathbf{1 9 - 2 0}$ \\
\hline 1 stage & 672 & 1486 & 2196 & 1474 & 6273 & 4973 & 5061 & 5480 & 5621 \\
\hline 2 stage & 324 & 251 & 187 & 251 & 162 & 130 & 125 & 129 & 137 \\
\hline
\end{tabular}

We offer the classification of the work shops.

Exhibition's work shops - the demonstration is used to illustrate skills for gests.

Educational work shops - the program involves children's from schools in designing and implementation of projects which will benefit their high level of knowledge. This involvement is executed through workshop, research, participation in great and creative competitions. Learning workshop, designed to develop creativity. Researcher workshop, which determing the level of knowledge and skills, set out to develop a theoretical model of professional science research.

Moscow Regional Center already has highly organized team of tutors, with consisting of the most experienced methodic. The possibility of implementing large-scale projects is ensured by an extensive research project in the fields of workshops festival directly to Russian Folk Art and craft.

It should be noted that the number of participants in the feestivals increase from year to year and the level of quality are mastered. In its first year (2011V 2012) 672 teachers with pupils were involved from 45 districts of Moscow region, in its second year (2012|2013) 1486 peoples from 54 districts were involved. The spectrum of across grades and ages expended from year to year. The Center become a major consolidating factor in promoting the processes of building sustainable spiritual and moral culture in Moscow region.

\section{References}

1. M.V. Galkina, Bulletin of the Moscow State University. Series: Pedagogy 4 (2017)

2. M.V. Galkina, E.Yu. Chirkova, Bulletin of the Moscow State University. Series: Pedagogy 1 (2021)

3. G.V. Cheremnykh, Teacher of the XXI century 1 (2016) 
4. E. Yu. Chirkova, Bulletin of the Moscow State University. Series: Pedagogy 2 (2019)

5. V. B. Koshaev, Bulletin of the Udmurt University. Series "Philosophy. Psychology. Pedagogy" 9 (2006)

6. I.V., Lovtsova L.A., Burovkina, Vestnik TSU 184 (2020)

7. V.V. Koreshkov, Nauka i shkola 5 (2017)

8. S.P. Lomov, The Ways and Means to Improve the Quality of Art and Aesthetic Education. The Shared Collection of Scientific and Methodological Works of Universities (Moscow, 2018)

9. S.P. Lomov, M.V. Galkina, P.D. Chistov, Art and Education 1(117), 77 (2019)

10. A.A. Moiseev, Proceedings of the Russian Annual Scientific and Practical Conference of Teachers, Postgraduates, and Students "Science, for the Benefit of Mankind 2016," dedicated to the 85th anniversary of Moscow State University (Moscow, 2016)

11. N.M. Sokolnikova, The history of fine art: in 2 Volumes: textbook (M., IC "Academy", 2006) 